\title{
As caminhoneiras: uma carona nas discussões de gênero, trabalho e identidade
}

JULice SALVAGNI ${ }^{1}$

\author{
${ }^{1}$ Universidade Federal do Rio Grande do Sul (UFRGS) / Escola de AdMinistração, Porto Alegre - RS, Brasil
}

\section{Resumo}

Este estudo considera caminhoneira a mulher que, para além de ser motorista de caminhão, opta por trabalhar com rotas longas. Desenvolvemos a problemática da elaboração da identidade de gênero no trabalho por parte da caminhoneira, especialmente do ponto de vista das características de uma atividade itinerante. A carona faz parte de uma pesquisa etnográfica, que visa à participação ativa da pesquisadora nas viagens da caminhoneira e das caminhoneiras enquanto locutoras dessa realidade. A identidade é vista a partir da noção de identificação, diferença e différance, a fim de pensar a realidade da caminhoneira de modo articulado com sua rotina itinerante. Gênero no trabalho trata dos formatos de legitimação dos papéis e identidades sociais solidificados na atualidade, sobretudo do ponto de vista da crítica feminista à biologia do sexo, que desconstrói o mito de suposta vantagem de força física. A compreensão de não lugares trata da transitoriedade característica da ocupação, já que os resultados apontam o desenrolar de uma identidade de fronteira. Abordamos o trabalho por meio do entendimento das hierarquias, dos poderes e da divisão sexista do trabalho, onde enfatizamos a maternidade como principal entrave à continuidade da mulher na atividade de caminhoneira. Por fim, destacamos que, embora a mulher esteja conquistando novos espaços de trabalho, as relações hierárquicas e de poder se reorganizam no interior das instituições, criando novas relações de gênero, mas não menos desiguais.

Palavras-chave: Caminhoneiras. Trabalho. Gênero. Identidade. Não lugares.

\section{Female truck driver: a journey of gender, work, and identity discussions}

\begin{abstract}
This study looks at female truck drivers who, besides being truck drivers, choose to work the long routes. The problem of gender identity in the workplace was addressed by analyzing the female truck driver, considering she performs an itinerant activity. Riding along is a constituent part of this ethnographic research, which aims at the researcher's active participation in the female trucker's journeys and the participation of the female truck drivers as a voice to be heard over this reality. Identity is seen from the notion of identity, difference and différance in order to see the female truck drivers' reality connected with their itinerant routine. Gender in the workplace is handled from the legitimation formats of social roles and identities, which are solidified nowadays, especially from the point of view of the feminist critique of sex biology. This critique deconstructs the myth of supposed physical strength advantage. An understanding of non-places was used to address the transience quality of occupation since the results point to the development of a marginal identity. We approach the work through the understanding of hierarchies, the powers, and the sexist division of labor proposed, where motherhood is emphasized as the main obstacle for female truck drivers to continue their occupations. At last, it is pointed out that although women are conquering new workspaces, hierarchical and power relations are reorganized within the institutions, creating new gender relations, but remaining unequal.
\end{abstract}

Keywords: Female truck drivers. Work. Gender. Identity. Non-places.

\section{Las camioneras: un viaje por las discusiones de género, trabajo e identidad}

\section{Resumen}

Este estudio considera 'camionera' a la mujer que, además de ser conductora de camiones, opta por trabajar con rutas largas. Desarrollamos la problemática de la elaboración de la identidad de género en el trabajo por parte de la camionera, especialmente desde el punto de vista de las características de una actividad itinerante. Carona (autostop) forma parte de una investigación etnográfica, que tiene como objetivo la participación activa de la investigadora en los viajes de las camioneras y de las camioneras como locutoras de esa realidad. La identidad es vista desde la noción de identificación, diferencia y différance, a los efectos de pensar la realidad de la camionera de manera articulada con su rutina itinerante. El género en el trabajo trata de los formatos de legitimación de los roles e identidades sociales solidificados en la actualidad, especialmente desde el punto de vista de la crítica feminista a la biología del sexo, que deconstruye el mito de la supuesta ventaja de la fuerza física. La comprensión de los no lugares aborda la transitoriedad característica de la ocupación, ya que los resultados apuntan al desarrollo de una identidad fronteriza. Enfocamos el trabajo a través de una comprensión de las jerarquías, los poderes y la división sexista del trabajo, donde enfatizamos la maternidad como el principal obstáculo para la continuidad de la mujer en la actividad de camionera. Finalmente, enfatizamos que, aunque la mujer esté conquistando nuevos espacios de trabajo, las relaciones jerárquicas y de poder se reorganizan dentro de las instituciones, creando nuevas relaciones de género, pero no menos desiguales.

Palabras clave: Camioneras. Trabajo. Género. Identidad. No lugares. 


\section{INTRODUÇÃO}

O tema das mulheres caminhoneiras, ao mesmo tempo que reúne discussões acerca das temáticas de trabalho e de gênero, tece nessas interlocuções os elementos identitários que derivam de papéis sociais que integram substancialmente uma ação performática e política. Assim, é a caminhoneira quem irá guiar uma construção teórica no que se refere ao percurso do tear sociológico dado à sobreposição desses aspectos pontuados e, da mesma forma, são essas as mulheres que, em suas individualidades, ajudam a escrever uma narrativa de suas próprias vidas, de seus itinerários.

Pegar uma carona na boleia, na linguagem da estrada, significa fazer parte da viagem da caminhoneira, pegar uma carona, já que na linguagem popular a boleia expressa o espaço do caminhão, seja na cabine ou na caçamba, onde os viajantes da estrada podem pleitear uma vaga temporária para um destino por vezes um tanto incerto. Nesse sentido, alcunhamos caminhoneira a mulher que, além de ser motorista de caminhão, opta por trabalhar com rotas longas e, assim, vive na estrada por um longo espaço de tempo. Essa especificidade da prática de trabalho é reconhecida por oferecer maior credibilidade aos trabalhadores e, consequentemente, maior remuneração. Para tanto, os motoristas que se propõem a percorrer grandes distâncias ficam na estrada por pelo menos 30 a 40 dias, dormindo e alimentando-se no próprio caminhão. Por essa, entre outras razões, trata-se de uma atividade ainda pouco exercida pelas mulheres, como elas mesmas esclarecem, além do agravante de ser um trabalho marcado pela informalidade (ANTUNES, 2008, 2011). A carona é a parte constituinte central do corpus de pesquisa, que visa à participação ativa da pesquisadora em uma das viagens da caminhoneira e à participação das caminhoneiras como locutoras dessa realidade a ser descoberta, o que é característico da etnografia. A mulher no volante, que no dito popular representa uma ameaça de perigo constante, é para nossa pesquisa o objeto de estudo.

A escolha por uma etnografia alicerçada por Augé $(1994,1999)$ nos permite problematizar a atividade da caminhoneira em conjunto com a trabalhadora e com seus colegas de profissão, desvelando, por meio do procedimento de tradução, elementos inerentes às relações de poder existentes no universo dessa atividade, eventualmente invisibilizados. Participaram da pesquisa 14 caminhoneiras e 3 caminhoneiros (os maridos delas) e foram feitas, além das observações participantes, 22 entrevistas ao longo dos 3 anos da coleta de dados (2012-2014). A construção dessa narrativa, composta por discursos verbais e imagéticos, possibilitou visualizar em profundidade os aspectos inerentes ao trabalho da caminhoneira e as questões de cunho teórico. Adotamos a análise de conteúdo proposta por Laurence Bardin (1995), uma das ferramentas que nos permite uma compreensão de cunho semântico - ou relativo ao sentido daquilo que advém da fala das caminhoneiras.

A possibilidade de ajudar a escrever sobre as variações da norma, mesmo que seja inevitável criar novas normas ao nomeálas, parece-nos um desafio posto e emergente ao tempo atual. A contemporaneidade, aquela mesma sociedade que borbulha por uma condição diferenciada nos modos de ser e estar, também mostra suas faces em reivindicação de certo controle diante do "descontrole" das matrizes normativas, sugerindo que o debate, embora esteja posto, está longe de ser encerrado. Assim, a divisão sexual do trabalho, que afetou de maneira desigual o emprego feminino e o masculino, atribui ao homem a função produtiva e de forte valor social agregado, enquanto a mulher é associada socialmente à função reprodutiva (HIRATA, 2003; KERGOAT, 2009; HIRATA e KERGOAT, 2007).

O objetivo desta pesquisa foi, portanto, identificar a elaboração da identidade de gênero e de trabalho da caminhoneira, que possibilite a compressão sociopsicológica pormenorizada dos processos sociais que se estabelecem com ela (e a partir dela) relações de trabalho masculinizadas. Para tanto, buscamos identificar a rotina de trabalho das caminhoneiras provenientes das narrativas, observando as ações cotidianas de gênero e trabalho, por meio do acompanhamento da caminhoneira em sua jornada de trabalho, seja no local do carregamento, na manutenção do veículo ou mesmo no percurso propriamente dito.

\section{IDENTIDADE DE TRABALHO E A PERFORMATIZAÇÃO DE GÊNERO}

Tecendo o conceito de identidade de forma intrinsecamente relacionada ao trabalho, entendemos que o sujeito se transforma por meio das relações sociais e ao mesmo tempo é agente transformador das instituições sociais com as quais se implica. Notamos, contudo, que embora essa imersão no trabalho pareça ser ousada - e em certa medida é -, há um nível de atuação que faz com que aos poucos os personagens sejam enquadrados por caricaturas que pertencem aos mesmos moldes anteriores estabelecidos a partir de relações de poder construídas e solidificadas histórica e socialmente. De modo geral, ratificamos uma 
mudança identitária que está "fragmentando as paisagens culturais de classe, gênero, sexualidade, etnia, raça e nacionalidade que, no passado, nos tinham fornecido sólidas localizações como indivíduos sociais" (HALL, 2000a, p. 9). No mais, tratando-se especialmente da relação com o trabalho, o conceito de "identidade" carece de estudos aprofundados que façam emergir significavas provocações de sentido entre o que é produzido nas relações a partir do espelho da alteridade.

Assim, a différance não só faz voz ao que é diferente dentro de uma relação onde a identidade é estabelecida, mas ainda propõe que não haja uma valoração qualitativa entre o que serve como parâmetro para a composição de um espaço híbrido na relação com o outro (HALL, 2003). Ao estabelecer essa propositiva, embebida da proposta de um significado variável, é possível não só pensar na transformação dos significados ao longo do tempo e nas diferentes culturas, mas considerar que esse significado nunca estará dado sem que, para isso, este esteja inserido devidamente em um contexto específico, nem em determinado momento. Levando o debate para a discussão da identidade de gênero, a inserção da mulher em uma atividade masculina a torna diferente não só dentro de seu ambiente que é majoritariamente masculino, mas também para suas demais relações sociais, já que ela deixa de ser uma mulher cuja escolha de trabalho é convencional.

Percebemos como central a necessidade de descortinar as identidades que se produzem nessas relações, especialmente ao âmbito trabalho-gênero por meio das narrativas que esboçam um movimento de performatização, o qual consiste na encenação de uma identidade social que essa mulher passa a considerar adequada (ou não) para determinada situação. Advogamos que, se por um lado as teorizações precisam dar conta de um contingente efêmero de diversidades, por outro, e dentro desse próprio contingente, a vida cotidiana vai mesclando referências de subversão com espaços altamente conservadores e que talvez sejam os predominantes, mas cuja lógica de adequação segue referência à norma social vigente. Tendo por base essa normatização historicamente construída, até aquilo que é considerado subversivo aos poucos vai sendo incorporado (ou performatizado) pela própria noção de norma não só às questões de gênero, mas também às discussões acerca do trabalho.

Essas falas são muito comuns entre as caminhoneiras. Todas, pelo menos em algum momento da conversa na carona, mencionam que alguém, normalmente próximo a elas, as desafiava no sentido de não julgá-las capazes de desenvolver essa atividade. Passado algum tempo, a própria noção social e familiar desses que a circulam passa do ridículo ao aceito, da tarefa que era impossível à corajosa. Ou seja, uma identificação e, consequentemente, a formação identitária advém dos modelos exigidos pelo trabalho em relação às formas binárias de gênero e sexualidade, evidentemente sempre contingentes. No caso das caminhoneiras, a oportunidade de trabalho lhes foi dada muito por uma demanda da organização propriamente familiar, já que em todas as narrativas há um homem, pai ou marido, abrindo a porta do caminhão para a mulher trabalhar, normalmente sem dissociar o vínculo de uma relação hierárquica.

A sobreposição de trabalho e gênero é indiscutivel no que diz respeito à elaboração da identidade, mas o interessante é justamente a ênfase em uma identidade de gênero produzida e reforçada pelo e no trabalho, por dimensões de poder inerentes ao modelo capitalista e de produção. Para tanto, é corriqueiro um deslocamento do papel social da mulher que a induz à performatização de uma identidade masculina, ou uma identificação, a fim de ser aceita e respeitada em seu espaço de trabalho, o que não ocorre em outras atividades.

Hall (2000b, p. 106) compreende a identificação como "uma construção, como um processo nunca completado - como algo sempre 'em processo'". Ao contrário do que se estabelece no senso comum, da identificação como o reconhecimento de iguais, a identificação "opera por meio da différance, ela envolve um trabalho discursivo, o fechamento e a marcação de fronteiras simbólicas, a produção de 'efeitos de fronteira" (HALL, 2000b, p. 106). As identificações podem ir ao encontro da identidade do sujeito ou diferenciar-se por completo. Nesse jogo de reconhecimento é que a identidade vai-se criando, e isso faz com que a produção de identificações não seja algo lógico e determinado. A identidade sendo "percebida como um construto complexo, multifacetado e sujeito às contingências temporais" (CARRIERI, PAULA e DAVEL, 2018), está passível, portanto, de ser permanentemente transformada. Por essa concepção, o estudo da identidade presume uma observação apurada do social e do meio onde a pessoa está inserida, como um espaço produtor de material simbólico. Nesse caso, consideramos o trabalho a fonte fundamental para a produção das identidades de gênero.

O trabalho ainda é uma instituição que modifica propositalmente os sujeitos para que estejam de acordo com seus modelos sólidos, "corretos", binários e heteronormativos. Trazemos à tona esse debate para provocar ruídos na estabilidade constituída e solidificada no que se supõe ser a identidade de trabalho e gênero na contemporaneidade; é uma forma política de tecer a teoria sociológica, que poderá refletir de modo direto no trabalho das caminhoneiras ou de outras mulheres em profissões tidas como masculinizadas. 
Essas teorias avançam e não destoam das compreensões estruturalistas, especialmente marxistas, de ler as relações sociais. Por exemplo, não podemos dizer que estejam extintos ou superados os processos de dominação de classe, baseados na exploração econômica; na verdade, eles continuam mais salientes e dolorosos do que nunca (SILVA, 2011). Mesmo que o pósestruturalismo aponte o caráter globalizador das desigualdades econômicas das relações de poder que estão por toda parte, é inevitável demarcar que "algumas formas de poder são visivelmente mais perigosas e ameaçadoras que outras" (SILVA, 2011, p. 147). Em suma, trabalhamos muito mais com a ideia de complementaridade de uma corrente à outra do que com a de qualquer forma de alternância entre elas. Essa premissa ajuda a pensar as diferentes correntes teóricas em diálogo, a fim de elucidar o espectro de relações entre trabalho e gênero sem sucumbir a uma única apreciação teórica ou mesmo temporal.

Ao abordar a fragmentação na pós-modernidade, podemos visualizar uma "estrutura deslocada, aquela em que o centro é deslocado, não sendo substituído por outro, mas por uma 'pluralidade de centros de poder'" (HALL, 2000a, p. 16). A identidade é a formação de múltiplas formas de ser que se sobrepõem e não eliminam uma ou outra e que são determinadas constantemente pelas relações sociais. Essas relações contemporâneas, das múltiplas e sobrepostas formas de identidade, permitem a ascensão do trabalho tido como masculinizado, por exemplo, assim como as mais diferentes configurações familiares que rompem com o tradicional em suas consagradas atribuições aos papéis de gênero. No caso das caminhoneiras, há uma construção histórica e social convidativa às transgressões dos papéis sociais, onde outras identidades vêm ganhando algum espaço para transitar, ainda que possivelmente estereotipadas.

Essas locuções teóricas são fundamentais para pensarmos a construção de uma política de identidade ou, nesse caso, de pósidentidade. Dentre as disputas do significado moral da identidade, Louro (2008) aponta que, enquanto alguns assinalam o caráter desviante, da anormalidade ou da inferioridade, outros proclamam a normalidade ou a naturalidade, mas todos parecem estar de acordo de tratar-se de um "tipo" humano distinto. A proposta de uma política pós-identitária desafia a pensar que uma compreensão sociológica da identidade de gênero no trabalho será possível a partir da tradução dessa performatização, no sentido mais teatral e interpretativo do termo, para evidenciar que, embora os discursos sejam transgressores, eles, paradoxalmente, são emoldurados em uma cena das relações sociais que os condenam a uma nova ordem de submissão; ou seja, outra forma de experimentar uma identidade de gênero no trabalho tem sido possível, embora se mantenha qualificada como aquém se observada em um contexto da identidade masculina dominante.

Não sendo enquadrada, muito menos enquadrante, a identidade é fixada conceitual e intencionalmente à noção de incompletude e de inclusão. Contudo, seria incoerente não considerar a adequação atribuída à identidade de gênero e de trabalho nas narrativas da vida cotidiana. Lidar apenas com a abertura teórica dos conceitos, sem partir das abruptas e preconceituosas demarcações que os fenômenos ganham nos contornos cotidianos, só faz produzir uma teorização suficientemente distante e aquém das relações sociais, portanto, igualmente distantes de uma política de pós-identidade. Com isso, propomos, de igual modo, certa flexibilização dos discursos feministas pós-estruturais, a fim de promover uma articulação com os conceitos de trabalho em seus mais variados sentidos.

Legitimando essa premissa, Scott (2005, p. 12) afirma que "reconhecer e manter uma tensão necessária entre igualdade e diferença, entre direitos individuais e identidades grupais, é o que possibilita encontrarmos resultados melhores e mais democráticos". Ou seja, a própria tratativa desses temas já faz que com as discussões se mantenham acesas e as transformações correntes, mesmo que em medidas inexpressivas. É importante que sinalizemos, antes de tudo, o conflito inerente à busca pelos direitos individuais e grupais, bem como na tentativa de operacionalização das igualdades em respeito às diferenças. Isso quer dizer que há uma construção social reforçada o suficiente para ser mantida, pelo menos até começar a ser localmente questionada, mesmo que individualmente, dentro de pequenos grupos, análogo ao que ocorre com a entrada da mulher na atividade de caminhoneira. Portanto, "a igualdade é um princípio absoluto e uma prática historicamente contingente. Não é a ausência ou a eliminação da diferença, mas sim o reconhecimento da diferença e a decisão de ignorá-la ou de levá-la em consideração" (SCOTT, 2005, p. 15).

Nesse contingente das diferenças se criam as identidades, sempre com uma perspectiva valorativa, ou seja, qualitativa das diferenças, mas que são individualmente algumas das premissas que contemplam as organizações dos grupos. As tensões no que diz respeito ao trabalho das caminhoneiras são colocadas e realocadas à medida que cada mulher passa a exercer a atividade e consolidar uma nova forma de relação entre as pessoas daquele grupo. Isso é visível na fala de um caminhoneiro quando diz ter sido alvo de recriminação do grupo por viajar junto com mulher e, logo, não desfrutar das festividades envolvendo prostitutas, por exemplo, o que demarcaria, segundo essa lógica, um espaço interditado à mulher. Ao que percebemos, para que a atividade da mulher, nesse caso, tenha sido possível, não só há um deslocamento da identidade feminina, que passa 
a ocupar uma atividade masculinizada, mas também do papel do homem que, abertamente, ao incluir a mulher em um ambiente proibido, ressignifica individualmente, e na relação, seja com a esposa ou com os demais colegas, um aspecto seu de identificação.

Ao mesmo tempo que há uma reviravolta dos papéis de gênero com a entrada da mulher nos espaços que eram considerados masculinos, ainda assim consideramos essa relação como parte de um poder que segue operando dentro da lógica de gênero. Mas será que não é possível elencar algumas mudanças significativas, mesmo dentro de um poder que não deixa de operar pela lógica binária? Ao pensar na atividade das caminhoneiras como possível afronta ao estatuto dominante de poder masculino, consideramos importante não só desvelar as próprias trajetórias dessa reorganização identitária mas, ainda, demonstrar a importância social e histórica dessas perturbações das noções de gênero, especialmente no que concerne ao campo empírico em questão.

Se pensarmos naquilo que as discussões de gênero ainda demandam e no que as teorias feministas vêm propondo como interpretação dos problemas de gênero, esse aspecto poderia soar quase irrelevante, haja vista a ênfase que os estudos dão aos processos efetivamente inomináveis presentes nessa composição. No entanto, trabalhamos com a ideia de que essas interferências na normalidade de gênero, mesmo que "sutis", são capazes de produzir reais e significativas mudanças nas realidades observadas.

A fixação da materialidade do sexo é o que daria, portanto, poucas saídas à própria transformação da compreensão de gênero, até ao longo da história, já que a própria noção de gênero teria um limite discursivo especialmente relacionado à concepção materializante do corpo por meio do sexo. Essa abordagem é especialmente interessante, já que não nega a dialética da relação da compreensão de "sexo" e "gênero", mas, ao mesmo tempo, expande-a significativamente, uma vez que, ao mesmo tempo que assume os limites dessa noção de correlação, questiona-se sobre as possibilidades de ampliação desses limites e no consequente efeito que esse alargamento teria ao conceito ou, melhor dizendo, à própria concepção da identidade no social.

Esse conflito fica explícito no que buscamos destacar, enquanto discussão de gênero, da elaboração de uma identidade que é intermediada por um trabalho masculinizado e, no caso, também itinerante. Nesse ínterim, perpassamos instâncias teóricas e empíricas, observando aspectos subjetivos, construídos e reconstruídos sobre os códigos sociais, portanto, coletivos que, por sua vez, são transpassados por diferenças esferas hierárquicas nas relações de poder.

Entendemos que a construção do gênero é independe do sexo, embora a identificação biológica ainda nos pareça um indicador, mesmo que seja levada em consideração a apropriação socialmente construída dessa correlação. Nicholson (2000, p. 2) lança algumas perspectivas epistemológicas, estabelecendo "se o próprio corpo é sempre visto através de uma interpretação social, então o 'sexo' não pode ser independente do 'gênero'; antes, sexo nesse sentido deve ser algo que possa ser subsumido pelo gênero". Isso torna o debate delicado pois, paradoxalmente, a sutileza dessas distinções não pode ser determinante, mas tampouco pode ser desconsiderada. Ou seja, "é por causa de uma certa desassociação prévia entre biologia e socialização que, num nível bem básico, muitas de nós somos quem somos" (NICHOLSON, 2000, p. 20). Nesse sentido, para a autora, "até mesmo quando a própria cultura associa o gênero à biologia, uma análise feminista que segue esses pressupostos fica incapaz de explicar aqueles que se desviam da norma" (NICHOLSON, 2000, p. 21).

Consideramos que, a exemplo das mulheres caminhoneiras, assumir para si uma profissão cujo estigma masculinizado ainda predomina quer dizer que se está disposta, de alguma maneira, a vir a ser reconhecida por essa profissão cujo vínculo com o ambiente masculinizado, grotesco ou machista é quase imediato, mesmo que vindo de recortes do senso comum. Quer dizer, consideramos a entrada nessa profissão ainda um fato significativo às mulheres, especialmente do ponto de vista da relação dessa profissão com uma identidade que supõe alguma transgressão diante das prerrogativas duais de gênero na sociedade. Assim, o gênero seria "o mecanismo segundo o qual se produzem e naturalizam noções do masculino e feminino, mas também como o mecanismo mediante o qual esses termos são desconstruídos e desnaturalizados” (PISCITELLI, 2008, p. 265).

Quanto à diferença como relação social, Brah (2006, p. 362) entende que "se refere à maneira como a diferença é constituída e organizada em relações sistemáticas através de discursos econômicos, culturais e políticos e práticas institucionais. Isso quer dizer que destaca a sistematicidade através das contingências". Esse processo de relacionalidades entre os contingentes subjetivos da construção identitária é o que permite o refazer dos indivíduos e dos coletivos que se unem e se sobrepõem na constituição da sociedade. 
Acerca da discussão biológica do sexo e da consequente configuração do gênero, Hird (2004) provoca a discussão em torno do sexismo a partir das construções científicas sobre as diferenças do corpo. A pesquisa centra-se nas teorias que remetem aos controles de "pecados" dos "corpos desviantes" e produzem degenerações polidas às opressões sexistas defendidas e dissolvidas pelas religiões ou pelos meios de comunicação. O foco está "na análise crítico-feminista que pode ser denominada a 'essência' da 'diferença sexual" (HIRD, 2004, p. 30, tradução nossa), sendo que a "essência" é entendida como a estrutura do esqueleto, gônadas, hormônios, cromossomos e genes, que se relaciona à forma com que a divisão sexual, do sexo e da sexualidade vai se constituir a partir de bases de conhecimentos científicos. A autora desconstrói as bases do conhecimento científico reivindicando limites para os parâmetros dele. Nesse sentido, a crítica feminista aponta significativos problemas metodológicos que são epistemologicamente limitados na composição da construção social para embasar esses argumentos.

Para a realidade das caminhoneiras, o debate em torno no corpo é fundamental para que possamos minimamente produzir uma voz dissonante diante das máximas socialmente conhecidas sobre a fragilidade do corpo da mulher. Quando levantada a temática das caminhoneiras, muitos dizem que elas só entraram nesse segmento graças à tecnologia recente empregada nos caminhões, que torna o trabalho mais leve. É evidente que esse argumento só pode ser usado para justificar a inferiorização da mulher no mercado de trabalho, já que, na prática, há muitos relatos de mulheres que dirigem caminhões manuais, muito embora seus maridos tenham caminhões automáticos. $O$ argumento reduz discursivamente a capacidade das mulheres e é construído sob a premissa das diferenças físicas dos corpos.

Hird (2004) revisa pesquisas em torno do esqueleto feminino que apontam uma estrutura mais fraca, destinada à amamentação das crianças, cuja estrutura torta e o ventre tenro colocariam as mulheres, segundo esse modelo científico, na condição de inferioridade em relação aos homens. Ademais, estudos sobre o crânio demonstram que o órgão feminino é menor e mais largo, sugerindo algum tipo de desenvolvimento incompleto. Diante disso, a autora destaca a construção científica baseada nas diferenças e que enaltece o corpo masculino à condição de superioridade.

A desconstrução dos aspectos físicos nos ajuda a pensar nas premissas atribuídas socialmente à mulher caminhoneira que a alocam em uma posição de inferioridade diante do homem, levando em conta os aspectos do corpo. Tomando por base esses estudos feministas, que questionam a ênfase que os estudos das ciências médicas e biológicas sugerem às diferenças do corpo, entendemos que a mulher é tão capaz quanto o homem de exercer qualquer tipo de atividade no trabalho, ainda que conte com uma demanda de força física. Ou seja, o natural não é ser diferente, mesmo quando observado o homem do ponto de vista da espécie, já que o que muda é a construção social feita ao longo dos anos a fim de demarcar as associações de gênero que direcionam a mulher a ocupar um lugar de inferioridade.

\section{ITINERÁRIOS DA IDENTIDADE: UMA DIREÇÃO RELATIVA}

Para entender a dinâmica das viagens, partimos do conceito de lugares e não lugares desenvolvidos por Augé (1994). O autor entende lugares como "conjunto de elementos, coexistindo dentro de certa ordem, e do espaço como animação desses lugares, pelo deslocamento de uma força motriz" (AUGÉ, 1994, p. 75) e descreve pelo menos três características das definições de lugares que nos sãos úteis especialmente para delimitar mais adiante o local de fronteira que o itinerário provoca e, portanto, a definição de não lugares. Contudo, há uma margem entre os conceitos de lugares e não lugares que faz com que esses espaços coexistam, especialmente no mundo contemporâneo com suas volatilidades. O lugar e o não lugar são "polaridades fugidas: o primeiro nunca é completamente apagado e o segundo nunca se realiza totalmente" (AUGÉ, 1994, p. 74). Entretanto, acima de tudo, é na figura do viajante e de seu itinerário que vive o maior arquétipo dos não lugares, já que o movimento de sujeitos e sua falta de referências a determinado espaço compõem em sua essência o não lugar.

Para Augé (1994, p. 99), "o personagem está em casa quando fica à vontade na retórica das pessoas com as quais compartilha a vida. O sinal de que está em casa é que consegue se fazer entender sem muito problema"; ou seja, para estar em casa, antes de ter uma casa no sentido literal, construída por paredes, telhado e janelas, é preciso sentir-se confortável o suficiente para que esse espaço alcance, com uma amplitude na sensação de relaxamento, identificar ser onde mais se quer estar. Nesse raciocínio, consideramos que as caminhoneiras, embora bem ajustadas e adaptadas ao caminhão, deslocam parte de sua vida familiar, social e de lazer para outra dimensão, que não é a do trabalho, talvez tampouco seja a da casa, mas que é como se fosse constituinte de um universo paralelo de construção de sentido que passa a ser construído no próprio percurso da viagem. 
Um itinerário é uma linha de um percurso, determinado ou não. No caso das caminhoneiras, também é uma linha de trabalho, com um sistema disciplinar de produção não menos rígido do que o das linhas de montagem nas esteiras. Para Canclini (1997), ao chegar à palavra "linha" caímos em uma zona de trânsito, o que pode evocar a situação dos migrantes indocumentados e, somamos à discussão, dos viajantes. Esse espaço fronteiriço, que é o espaço da estrada, da via, da condição do movimento, faz eclodir uma ampla invenção especular das próprias cidades, um produto híbrido no qual o viajante assume um papel central. O itinerário, portanto, é "sinalizado por etapas e pontos fortes, compõe com ele um lugar 'de sentido único' e um 'espaço'" (AUGÉ, 1994, p. 83). Ou seja, por mais móvel que seja o itinerário do viajante, por mais incerto, relacional e cambiante, ainda assim há uma apropriação de sentido que se dá por meio "das convivências de linguagem, dos sinais da paisagem, das regras não formuladas do bem viver, [já que] é o não lugar que cria a identidade partilhada dos passageiros" (AUGÉ, 1994, p. 92).

O deslocamento da atividade faz com que ela dê ênfase ao fato de sentir-se uma forasteira ao retornar à própria cidade. Não saber mais onde fica o salão nos leva a pensar em uma dimensão de espaço e de tempo suficientemente grande para gerar na trabalhadora uma impressão de não pertencimento. Os outros, nesse caso, vão paulatinamente se distanciando de suas próprias experiências de vida e concepções de mundo, que cada vez mais passam a ser compostas dentro da boleia. Essa distinção, seguindo na concepção de Augé (1994), é imperativa na construção da identidade e, portanto, indexador máximo dos modos de relacionar-se da sociedade em seus mais diversos estratos, produzindo normatizações dos padrões de identidade que sufocam e limitam a construção de sentido, individual e coletivo, que venha a ser desviante daquilo que é histórica e culturalmente convencionado pelos grupos dominantes, onde não se descartam as próprias instâncias acadêmicas.

As caminhoneiras, as mulheres do trânsito, que estão em trânsito, representam em si o símbolo do abandono de tudo aquilo que é unificado. O sujeito que viaja é, ele próprio, "dividido, fragmentado e cambiante [...] de modo tal que só o movimento é capaz de garantir algum equilíbrio ao viajante" (LOURO, 2008, p. 13). Isso é significativo, ao passo que importante é o andar e não o chegar, até porque o viajante nunca chega. Ele é feito de percursos, de trajetórias e de lugares, além das partidas e das chegadas.

As mulheres, portanto, ao passo que se dirigem pioneiramente à estrada e iniciam seu percurso de trabalho em um ambiente que é considerado o oposto ao delas, ou melhor, que determina pelo não ser o que elas são, ocupam um lugar (não lugar) que é o espaço do nômade. Esse é o espaço da renúncia e da desconstrução de qualquer senso de identidade, já que "recusam a fixidez e a definição das fronteiras, e assumem a inconstância, a transição e a posição 'entre' identidades como intensificadoras do desejo" (LOURO, 2008, p. 21). Mesmo no que se pronuncia acerca da entrada da mulher no mercado de trabalho, de que há certa igualdade de tratamento, salários e oportunidades, faz com que seja ainda mais abstrusa a identificação das formas coercivas que se produzem nessa relação. Os papéis são definidos, ainda, a partir das diferenças duais de gênero e fazem com que se criem espaços de trabalho que são tipicamente adequados aos seus estereótipos.

Quando o sujeito não se ajusta à condição da norma socialmente composta e se não consegue subvertê-la (ou, quando muito, subverte-a pouco), o drama social como proposto pelo autor passa a ser performatizado. Ou seja, "o papel oferece o padrão segundo o qual o indivíduo deve agir na situação. Tanto na sociedade quanto no teatro, variará a exatidão com que os papéis fornecem instruções ao ator" (BERGER, 1978, p. 109). Disfarce é um termo que nos é especialmente interessante por conseguir representar, ao mesmo tempo, a figuração do papel social e o desconforto de não sermos quem queremos, efetivamente. Em outro aspecto, é relevante questionar a existência de um mundo, ou mesmo de uma cena, onde não haja disfarce algum, em nenhuma medida. Ou seja, os disfarces nos parecem importantes e até de certo modo saudáveis se usarmos as prerrogativas psicanalíticas acerca dos mecanismos de defesa possíveis diante das situações angustiantes; no entanto, de modo inevitável, parece-nos que o próprio curso evolutivo (mas não necessariamente evoluído) da sociedade depende dos desvelares dos disfarces, pelo menos até transformar a verdadeira face em um novo disfarce.

Na narrativa das caminhoneiras, o que se propõe seria uma espécie de reformulação das estruturas de trabalho, de classe, de sociedade, muito no diálogo com as reformulações contemporâneas de gênero que não poderiam ter sido abordadas nesse sentido por Karl Marx, justamente por não ter sido parte do cenário de sua época, também. Ou seja, a reapropriação do contexto social - cuja relevância aqui se faz na expansão, retificação e incorporação de novos elementos -, mais do que uma crítica ao estruturalismo é uma tentativa de reescrever os percursos das relações de poder imersos em novos códigos significantes, cujo próprio trajeto se dá na expropriação das próprias formas que o trabalho adquire da atualidade por meio das nuances que há nos meios de produção. Nossa intenção, cabe ressaltar, está muito longe de pensar acerca de uma nova perspectiva teórica, mas, quando muito, salientar pontos dissonantes e acordantes das teorias revisadas para fins de entendimento dos fenômenos inerentes ao debate de gênero no trabalho aqui traçados. 
Em tempo: há preocupações acerca das "amarras" teóricas que, sendo ausentes, poderiam criar alguns perigos ao multiculturalismo, como é o caso de tornar-se binário justamente por representar um universo de questões culturais que "não as dominantes", mostrando-se apenas como resposta opositora de uma verdade já sabida. Contudo, a noção constante de um movimento acerca das leituras sociais, que não negam as brutalidades das realidades econômicas e de classe, mas aprofundam o debate de um ponto de vista a ampliar as discussões sobre os sujeitos e suas subjetivações, parece-nos um caminho inevitável e pertinente à necessidade de desmanchar certos rótulos sem deixá-los carentes de sentido.

Quanto ao trabalho da caminhoneira, este também é justificado na atualidade como sendo possibilitado apenas pelo avanço da tecnologia que é incorporada, sobretudo, ao funcionamento do caminhão. Se não fosse esse avanço tecnológico, afirmam muitos, a viabilização da mulher na condição de caminhoneira não seria possível, dada a demanda do uso da força física para a realização da atividade. Esse discurso, contudo, é desconstruído não só pelas teorias que abordamos, mas pela própria história das mulheres participantes, já que muitas dirigem um caminhão manual que, portanto, exige força física, ao contrário de seus maridos ou colegas que dirigem caminhões automáticos. Isso mostra que trabalho masculino e força não têm a menor ligação; ao contrário, apenas reforça mais um dos muitos discursos sexistas que foram (e são) historicamente constituintes da forma de organização do trabalho que demarca não só divisões, mas, sobretudo, qualificações ao trabalho masculino como sendo de qualquer ordem de superioridade e não de dominação.

Sobre os processos do trabalho, é perceptível a interferência dos sistemas taylorista e fordista na atividade das caminhoneira, que centralizam em sua concepção da busca pela economia de tempo atrelado a novos processos de gestão do trabalho (NEFFA, 1998). Referências a esse modelo podem ser percebidas especialmente na lógica do encurtamento do tempo livre e na tentativa de acelerar ainda mais o tempo de trabalho. O percurso a ser cumprido é sempre medido pelo menor tempo. Se um conseguiu, todos os outros também deverão fazer no mesmo tempo, o que ajuda a compor o cenário violento a que é submetido o profissional das estradas. Se entre os caminhoneiros do sexo masculino já há uma cobrança, o agravante da caminhoneira se encontra justamente na legitimação de sua capacidade para o trabalho na medida em que consegue atingir o "tempo do homem".

As particularidades do trabalho, das atividades e das condições de operação desse e nesse setor devem ser cuidadosamente consideradas. Nesse aspecto, pensando no trabalho da caminhoneira, mesmo fazendo as devidas distinções entre o entendimento dos processos de trabalho derivados da produção e dos serviços, podemos destacar especialmente dois aspectos fundamentais, que hoje ilustram a rotina de trabalho desses profissionais e sugerem ser relacionados, pelo menos em parte, à formulação proposta pelo toyotismo, já que há uma linha em comum no aspecto da produção de mecanismos disciplinadores do trabalho que são criados na fábrica, mas que se reproduzem no setor de serviços, mesmo longe do olhar de controle dos supervisores e por meio de outras regras que são incorporadas à atividade laboral e perpassam os limites físicos da empresa para operar em diferentes espaços de trabalho.

Nesse sentido, há uma ruptura, ou melhor, uma reordenação dos campos de poder sempre que algo se altera a partir daquilo que estava estipulado. A entrada da mulher no mercado de trabalho e, recentemente, sua ocupação em trabalhos considerados masculinizados nos levam à emergente produção de outro olhar sobre o desenrolar dos fenômenos. Essa compreensão nos possibilita avaliar as mais sutis manifestações de poder que são desconsideradas nas leituras da atividade da mulher caminhoneira, passando ao entendimento das práticas que são legitimadas dentro desse campo e exercem um significativo poder de transformação nas ações dos agentes envolvidos.

A inclusão da mulher no trabalho compõe o que Antunes (2005, p. 47) denomina o "(novo) caráter multifacetado do trabalho". Nessa perspectiva, haveria uma sobreposição do trabalho doméstico e institucional, "aumentando as formas de exploração do contingente feminino" (ANTUNES, 2005, p. 80). O trabalho, socialmente construído junto com outros tantos aspectos da humanidade, paralelamente à dominação do masculino, foi ditando formas diferentes de labor para homens e mulheres. Primeiramente, o fato das mulheres ficarem em casa para cuidar dos filhos e, em contrapartida, os homens se dedicarem ao trabalho, foi marcando socialmente o gênero da dominação. Colocamos em relevo as discussões feministas, o que inclui pensar a identidade que, depois de ser desvelada em suas particularidades, deixa-nos como herança um compromisso permanente com a interlocução do trabalho. As novas formas de ser e estar que produzem outros modos de socialização não deixam de pertencer aos e reinserir-se nos já sabidos modos estruturantes e hierarquizados de produção; agora, contudo, outra vez passam a ser ressignificados sob outros véus do poder. 
Há elementos presentes no jogo de poderes que sugerem uma tentativa do homem de promover a manutenção das "estratégias de dominação que sustentam a construção binária da diferença dos sexos" (VARIKAS, 1994, p. 67). Entre eles, contudo, destacamos inicialmente a produção da violência contra a mulher como principal ferramenta reprodutora da exploraçãodominação. O poder masculino "atravessa todas as relações sociais, transforma-se em algo objetivo, traduzindo-se em estruturas hierarquizadas, em objetos, em senso comum" (SAFFIOTI, 2001, p. 120).

Por esse aspecto, toda pesquisa de gênero demanda um exercício crítico ancorado na transposição dos modelos de poder legitimados. Essas questões são pautadas por uma resistência invisível em que as experiências cotidianas - as representações - são sempre pensadas do ponto de vista de classe e de gênero, de modo articulado (SOUZA-LOBO, 2011). A autora afirma que os cargos são sexualizados, uma vez que, por exemplo, "a resistência masculina é descrita como uma relação de poder [em contrapartida] a das mulheres como resistência, irresponsabilidade, falta de interesse" (SOUZA-LOBO, 2011, p. 87).

Dessa forma, salientamos que, em se tratando de desigualdades, é justamente o somatório das evidências de exclusão que confere a determinado fenômeno maior expressividade dentro do meio social. Ou seja, mulheres caminhoneiras, embora sujeitas à discriminação de gênero, ao preconceito e, por vezes, ao assédio no trabalho, por exemplo, estão longe de protagonizar o pior dos cenários de desigualdade. Há uma lacuna nos Estudos Organizacionais que deve intercambiar para a acumulação do capital outros elementos, como classe, raça, etnia ou mesmo a orientação sexual, identificando a precarização na intersecção com as categorias de gênero, classe, raça e etnia (BLAY, 2001; PISCITELLI, 2008; HIRATA, 2002, 2009, 2016; KERGOAT, 2009). Contudo, a temática não se mostra menos importante porque há o deslocamento da mulher para o trabalho masculinizado, que não pode deixar de ser evidenciado.

Nesse sentido, o trabalho é, inegavelmente, um alicerce central na produção de subjetividade e, consequentemente, de sofrimento psíquico, que deve ser visto em conjunto com o amplo leque dos riscos e suas invisibilidades. Além do risco de acidentes, compreendemos que, atualmente, os riscos seguem na esfera do invisível - totalmente relacionados aos fatores sociopsicológicos (SALVAGNI, 2012). Ao mesmo tempo que o risco é um elemento constitutivo da subjetividade dos trabalhadores, as experiências pessoais do sujeito comporão sua representação do risco no trabalho e é especificamente o que se produz nessa relação, agravado pelos processos de tempo, aceleração e demais condições de trabalho. Por essa razão, torna-se indispensável uma interlocução das categorias de gênero com o trabalho. As premissas teóricas não podem mais ser vistas sem que façamos uma apropriação do que há de específico ao trabalho da mulher. Este estudo buscou desvelar as proeminências que são acentuadas em uma perspectiva de dominação quando se trata do trabalho realizado pela mulher.

\section{CONSIDERAÇõES FINAIS}

A intenção de dialogar com diferentes propostas teóricas, como o estruturalismo e as teorias pós-modernas de gênero e identidade, cabe para mostrar que, se por um lado as concepções de alienação e dominação no trabalho postuladas pelo marxismo se mantêm atuais, por outro é emergente a construção de um pensar sociológico que dê conta da contingência da identidade de gênero aplicada a essa concepção crítica das formas das relações de trabalho. Essa análise, portanto, contribui com o constante fazer das teorias e práticas administrativas, no sentido de fomentar que os debates sobre o trabalho e suas intersecções tenham um olhar a partir dos Estudos Organizacionais, especialmente em tempos nos quais os direitos sociais têm sido fortemente ameaçados no Brasil.

No que tange ao gênero, é indiscutível que as questões referentes ao corpo, ao esqueleto e à força em nada impedem que a mulher desenvolva as atividades ditas masculinizadas. Faz parte do discurso do senso comum, quando não reforçado no meio científico, enfatizar a suposta superioridade masculina não só no que diz respeito à destreza ou ao vigor, mas, especialmente, usando como argumento a força física. Dessa forma, as mulheres são parte de uma construção social que vem reforçando ao longo do tempo a ideia de que elas não são capazes de realizar determinadas atividades sob a justificativa de uma incapacidade física. Em um sentido político, é fundamental que esse aspecto das condições físicas associadas ao gênero seja rebatido, já que ele embasa uma série de preconceitos e freia as ações das mulheres diante de perspectivas profissionais. Ao se verem rodeadas por um discurso de incapacidade, as mulheres, de modo geral, incorporam uma verdade inventada que as distâncias das possibilidades múltiplas de ser e estar no convívio social. É fato que a maternidade provoca um rompimento da atividade da mulher quanto ao serviço pesado, mas esse evento é momentâneo e em nada deveria intervir em uma construção de trabalho. 
O não lugar, o espaço do itinerante, é marcado pelo lugar do masculino. A mulher, segundo os papéis de gênero sexistas, pertence à casa, nada mais. Esse lugar de passagem, cujas atividades mais comuns são ligadas aos meios de transporte, seja ele piloto de avião, marinheiro, maquinista, trabalhador de uma base petrolífera ou até taxista, assim como a do caminhoneiro, são as que supõem um desprendimento do lar, uma desvinculação das ordens rotineiras dos cuidados com a casa ou com a família, o que é bem aceito socialmente quando ocupado pelo personagem masculino.

Uma mulher, portanto, ao se deslocar de casa para trabalhar e viver em uma estrada da incerteza supõe abdicar, inclusive, de sua própria imagem de mulher que Ihe foi atribuída desde menina. Ou seja, ela assume um deslocamento de gênero, daquilo que foi prenunciado a ela, no momento em que deixa a casa e a noção de família tradicional, mesmo que momentaneamente, para dar prioridade ao trabalho. No entanto, ainda que jogue o jogo do masculino, assumindo para si condutas e normas que fazem parte do universo do qual ela quer fazer parte, ainda assim ela busca constantemente, por meio de seus discursos e ações, marcar um papel feminino, de aparente fragilidade e vaidade, já que esses são os códigos que lhe foram historicamente ensinados a selar. Por um lado, portanto, ela marca aquilo que quer que os outros saibam: que continua sendo mulher; por outro lado, rende-se à iminência de um ambiente carregado por sentidos masculinos, os quais ela não pode negar, precisa dialogar para ser aceita e assume para si, haja vista que o trabalho, em sua essência, é pautado pela sujeira, pela força física e por certa pujança que também pertence ao masculino. Assim, ela não tem outra saída senão se marcar com os códigos deles, para que o trabalho seja feito, para não ser motivo de deboche e para mostrar a si sua própria superação. Contudo, tanto quando o andar do caminhão vai tornando-a mais caminhoneira, a trajetória de trabalho masculinizada vai fazendo com que siga criando um sentido para si, em sua função, em sua feminilidade. Ao elaborar sua identidade com e na estrada, ela passa a perceber o mundo sob outros prismas: vislumbra um alargamento da fronteira entre aquilo que já conhecia do mundo e o que tem a conhecer e, mais do que isso, explora a si mesma em suas limitações e possibilidades. Ela se considera, com todo o direito, guerreira de si mesma.

Quanto à questão do trabalho, está claro que a inserção da mulher em uma atividade masculinizada não é suficiente para fazer com que se altere a lógica da dominação de gênero. É fato que há ousadia, quebra da regra social por parte da mulher que se dispõe ao que consideramos um trabalho sujo, mas isso a coloca em disposições desiguais no que se refere aos papéis do feminino e do masculino na sociedade - como em qualquer outra profissão.

É apropriado sinalizar que a inclusão das mulheres em atividades tipicamente masculinizadas, ao mesmo tempo que demarca uma nova possibilidade laboral ao público feminino, ampliando e reforçando a luta pela igualdade nas condições de trabalho, também produz a criação de novas relações de dominação inerentes aos próprios grupos. Isso quer dizer que há de ter-se cautela com as aparentes diluições das desigualdades sociais de gênero no trabalho, uma vez que estas, ao mesmo tempo que mostram avanços importantes, também recriam de forma velada novas e não menos severas formas de dominação. Nessas entrelinhas vislumbramos lacunas significativas para futuros estudos sobre trabalho e gênero, que deverão ser perspicazes na tarefa de saber descortinar as novas facetas da opressão.

Além disso, acerca do lugar de passagem do viajante, consideramos que o anonimato e a solidão presente na atividade da caminhoneira levam a crer que ela poderá não cuidar da aparência na ausência da pesquisadora nas viagens. Ou seja, intuímos que a pesquisadora, por ser uma visita ao caminhão, possa ter estimulado nas caminhoneiras determinadas práticas acentuadas de cuidados de si. Se não fosse essa interferência da pesquisa, possivelmente não usaria maquiagem, mas ela o faz para se mostrar mais feminina, já que supõe, por estar em um ambiente reconhecido como masculino, que pode vir a ser confundida em meio dele. Mais do que isso, ela quer se destacar. Quer mostrar que continuou mulher mesmo dirigindo um caminhão, que pôde anunciar uma forma diferente de fazer seu trabalho, que pôde pintar de batom a lona marcada pelo machismo.

Assim, há muito ainda a fazer em termos políticos e acadêmicos que descortinem os novos rostos da exploração, da dominação e do machismo contemporâneo. Vislumbramos as caminhoneiras como protagonistas de um confronto com as normatizações sociais. Muito além de uma aventureira forma de trabalho, lado a lado com os inúmeros riscos da estrada, essas mulheres estão ajudando a refazer a própria concepção do feminino, reforçando que o lugar da mulher é onde ela quiser. "Ao fomentar a luta pela igualdade de gênero no mercado de trabalho, questionamos os padrões heteronormativos, sexistas e binários que, historicamente, cerceiam a liberdade das identidades, condenando-as a viver sob os ajustes da norma.". 


\section{REFERÊNCIAS}

ANTUNES, R. O caracol e sua concha: ensaios sobre uma nova morfologia do trabalho. São Paulo: Boitempo, 2005.

ANTUNES, R. Desenhando a nova morfologia do trabalho: as múltiplas formas de degradação do trabalho. Revista Crítica de Ciências Sociais, n. 83, p. 19-34, 2008.

ANTUNES, R. Os modos de ser da informalidade: rumo a uma nova era da precarização estrutural do trabalho? Serviço Social \& Sociedade, n. 107, p. 405-419, 2011.

AUGÉ, M. Não lugares: introdução a uma antropologia da supermodernidade. Campinas: Papirus, 1994.

AUGÉ, M. O sentido dos outros. Petrópolis: Vozes, 1999.

BARDIN, L. Análise de conteúdo. Porto: Ed. 70, 1995.

BERGER, P. Perspectivas sociológicas: uma visão humanística. 4. ed. Petrópolis: Vozes, 1978.

BLAY, E. A. Um caminho ainda em construção: a igualdade de oportunidades para as mulheres. Revista USP, n. 49, p. 82-97, 2001.

BRAH, A. Diferença, diversidade, diferenciação. Cadernos Pagu, n. 26, p. 329-376, 2006.

CANCLINI, N. G. Culturas híbridas: estratégias para entrar e sair da modernidade. São Paulo: Edusp, 1997.

CARRIERI, A. P.; PAULA, A. P. P.; DAVEL, E. Identidade nas organizações: múltipla? fluida? autônoma? Organizações \& Sociedade, v. 15, n. 45, p. 127-144, 2008.

HALL, S. A identidade cultural na pós-modernidade. 4. ed. Rio de Janeiro: DP\&A, 2000a.

HALL, S. Quem precisa da identidade? In: SILVA, T. T. (Org.). Identidade e diferença: a perspectiva dos estudos culturais. Petrópolis: Vozes, 2000b. p. 103-133.

HALL, S. Da diáspora: identidades e mediações culturais. Belo Horizonte/Brasília, DF: Ed. UFMG/Unesco, 2003.

HIRATA, H. Globalização e divisão sexual do trabalho. Cadernos Pagu, n. 17-18, p. 139-156, 2002.

HIRATA, H. Por quem os sinos dobram? Globalização e divisão sexual do trabalho. In: TEIXEIRA, M. (Org.). Trabalho e cidadania ativa para as mulheres: desafios para as políticas públicas. São Paulo: Coordenadoria Especial da Mulher, 2003. p. 9-11.

HIRATA, H. A precarização e a divisão internacional e sexual do trabalho. Sociologias, v. 11, n. 21, p. 24-41, 2009.

HIRATA, H. Subjetividade e sexualidade no trabalho de cuidado. Cadernos Pagu, n. 46, p. 151-163, 2016.

HIRATA, H.; KERGOAT, D. Novas configurações da divisão sexual do trabalho. Cadernos de Pesquisa, v. 37, n. 132, p. 595-609, 2007.

HIRD, M. Sex, gender, and Science. Houndmills: Palgrave Macmillan, 2004.

KERGOAT, D. Divisão sexual do trabalho e relações sociais de sexo. In: HIRATA, H. et al. (Org.). Dicionário crítico do feminismo. São Paulo: Ed. Unesp, 2009. p. 67-75.

LOURO, G. L. Um corpo estranho: ensaios sobre a sexualidade e a teoria queer. Belo Horizonte: Autêntica, 2008.

NEFFA, J. C. Los paradigmas productivos taylorista y fordista y su crisis: una contribución a su estudio, desde el enfoque de la "Teoria de la Regulación". Buenos Aires: Lumen, 1998.

NICHOLSON, L. Interpretando o gênero. Revista Estudios Feministas, v. 8, n. 2, p. 8-41, 2000.

PISCITELLI, A. Interseccionalidades, categorias de articulação e experiências de migrantes brasileiras. Sociedade e Cultura, v. 11, n. 2, p. 263-274, 2008.

SAFFIOTI, H. I. B. Contribuições feministas para o estudo da violência de gênero. Cadernos Pagu, n. 16, p. 115-136, 2001.

SALVAGNI, J. Tempo, trabalho e risco: uma análise das temporalidades nas relações de trabalho. Confluências, v. 12, n. 1, p. 213-237, 2012.

SCOTT, J. W. O enigma da igualdade. Estudos Feministas, v. 13, n. 1, p. 11-30, 2005.

SILVA, T. T. Documentos de identidade: uma introdução às teorias de currículo. 3. ed. Belo Horizonte: Autêntica. 2011.

SOUZA-LOBO, E. A classe operária tem dois sexos: trabalho, dominação e resistência. São Paulo: Fundação Perseu Abramo, 2011.

VARIKAS, E. Gênero, experiência e subjetividade: a propósito do desacordo Tilly-Scott. Cadernos Pagu, n. 3, p. 63-84, 1994.

Julice Salvagni

ORCID: https://orcid.org/0000-0002-6334-0649

Doutora em Sociologia pela Universidade Federal do Rio Grande do Sul (UFRGS). Professora adjunta no Departamento de Ciências Administrativas da

UFRGS, Porto Alegre - RS, Brasil. E-mail: julice.salvagni@ufrgs.br 